\title{
Ideology and health care policy:On the fairness and efficiency of health balance
}

\author{
Zhou Jing', Zhang Zizi' ${ }^{1}$, Zhu Heng ${ }^{2}$ \\ ${ }^{1}$ School of Economics, Huazhong University of Science and Technology, Wuhan, P.R.China, \\ 430074 \\ ${ }^{2}$ Propaganda Department of Party Committee, Hubei Institute of Fine Arts, Wuhan, \\ P.R.China, 430074 \\ (E-mail: zhoujing840305@eyou.com, fisherzzz@qq.com, \\ zhuheng84212@sina.com,)
}

\begin{abstract}
In a particular social environment, Ideology plays a critical role in the adoption and implementation of health care policies. Actually, the subtle changes in ideology are related to the unfavorable phenomenon of "unfair and inefficient" appeared in health field during the period of economic transition. This paper demonstrates the existence of this influencing mechanism by research on the change of Chinese health care policies. Besides, this paper also offers a few suggestions to rebuild the balance of an "equity and efficient" in the health field.
\end{abstract}

Keywords: ideology, health care policies, equity, efficiency

\section{Introduction}

Since the end of 1970s, China has made an impressive progress in the economic system transition and sustained a high speed of continuous economic development for over 30 years, which is called a "Chinese miracle" by economists. Along with the transition, in the field of medical service which is closely related to people's health and comprehensive quality, many severe problems have emerged: on one hand, from the perspective of the institutional functions of public policies, the weakness of public health service and unequal treatment of the public service have become more serious, and the fairness of medical treatment and the equality of health are questioned by the society; on the other hand, from perspective of the organizational efficiency, the present research show that most public medical institutions in China are featured by high cost but low efficiency, especially the governmental institutions which are gradually losing the important role of "saving the injured and serving for the public". These institutions made little contribution to the improvement of rural and urban residents' health, resulting in an "unfair-inefficient" situation in public health field.

In 2000, the World Health Organization assessed the medical system of 191 countries, and China ranked 144, but the 4th from bottom sorted in order of financing contribution equality. However, we still remember clearly that in 1970s, China was once chosen as the "model of developing countries in solving medical problems". We cannot help asking: what led to the change and the worst combination of fairness and efficiency? The paper is trying to discuss the problem of choosing and implementing national medical policies from the perspective of ideology. It is believed that the medical reformation should be based on re-examination of the value of fairness and the formulation of policies on both fairness and efficiency, ensuring the best outcome of the national public medical service institutions, shouldering the main responsibility of citizens' medical welfare, and improving their health level.

The paper is structured as follows: the first part is the analysis of several ideological forms which are related to fairness value and instructive to the formulation of medical service policies; the second part is the 
historical review of the evolution of Chinese medical system and policy choices; and the final part is some constructive suggestions to approaching the rebalance of "equity and efficiency".

\section{Several ideologies referring to the fair value}

The word "Ideology" was first coined by French philosopher Destuttde Tracy in 19th century which refers to "science of ideas". After several years' development, it came into a relatively integrated ideological theory with Karl Marx's continuation and evolution. In his work, he formulates a thesis that ideology is kind of comprehensible imagination or a way to observe things and also a set of ideas set by the ruling class to all members of society. Ideology has several aspects, including political, social and economic, but their general character is political which marked abundance in political ideology. In social studies, political ideology is a set of concepts and principles used to interpret how the society is operating. It has some certain value judgments, providing a fundamental value framework for social rights, even depicting a blueprint of social order. And from the perspective of fairness value which would have a great influence on health policy, this paper classifies ideology into two categories, liberalism and equalitarianism.

\subsection{Liberalism}

John Locke, the early liberal thinker, is the first person who put forward the Social Contract Theory. He claimed that private individuals had a fundamental right to life, liberty and property and government should be subject to the consent of the governed. For those liberals, politics, economy and social life of one country must aim at defending individuals' freedom and rule of law should replace absolutism in government. Hence, in the matter of health care, those liberals often regard it as part of "social reward system". They argue that the government shouldn't monopolize the supply for health care, which is supposed to depend upon medical insurance even medical assistance ought to be the principal way to improve the state of lacking health care amongst disadvantaged groups. In one word, intervention by government should be minimized.

\subsection{Equalitarianism}

It is defined as a political doctrine that all people should be treated as equals and have the same legal, political, economic and civil rights. And from the standpoint of equalitarianism, "Equal opportunity to access to health care is a civil right, similar to voting right and fair judgment right, shouldn't be limited to income and fortune". And what's need to be stressed out is that as Gillon put it, "distribution according to one's needs" not only consists in equalitarianism but also presented in Marx's works, coupled with another principle as "from each according to his ability". In the background of medical care, the principle of "from each according to his ability" can be interpreted as "People pay according to their ability". This shows, in the matter of medical equality, these two principles do have the consistency.

\subsection{Disputes about "Priority" and health care system}

The conflict between liberty and equality has appeared as a problem of cardinal importance in Rawls's philosophy. In order to balance the conflict of intrinsic values within the principles of justice, Rawls put forward the theory of "lexical order", i.e. the first principle of justice known as liberty is prior to the second principle of justice known as equality.

However, on the contrary, Ronald Dworkin favored the priority of equality. He believed that "We have agreed on an abstract equalitarianism principle: government should let all residents live a better life and show a equal care to everyone's living. It's an indication that equality has been the most important value which must be put into practice in the contemporary society. And according to Dworkin's view, equality is the supreme virtue in society.

The above two contentious views respectively point to different health care systems. Equalitarianism suggests public financing should be placed on dominate position, and medical service should be distributed according to "needs", medical financing pay according to the public payment capacity. While liberalism, on the contrary, prefers a health care department mainly depends on individual financing. Medical service provided according to the willingness and capacity to pay, which results in the degree of communal participation is low and the 
disadvantageous groups have only limited medical service in the minimum standard. Generally speaking, policy-makers in Europe tend to equalitarianism, emphasizing the government endeavors in ensuring each citizen the equal opportunity to enjoy health care. But those policy-makers in United States seemed rarely making an agreement on the fairness issues in health care field, nor declare clearly all citizens have general and equal opportunity for health care service.

\section{Changes in ideology and health policy}

\subsection{Brief review of the course of china's health policy change}

The formulation of health policy is significantly affected by Chinese market-oriented reforms, as well as social ideology change aroused by the improvement in consciousness of "scientific development" since the late of last century. This paper intent to use the late seventies of last century (started to implement the "household responsibility system") and the beginning of this century as the two separated points, to explain the change course of health policy.

\subsubsection{Start-up period of medical and health service system}

we began to set up our health care system in a destitute state from the late 1960s to 1970s.During that time, the health development principal -"prevention first" was put forward. Then, health care system has been constantly improved. Multi-level urban and rural health service network has been gradually established in urban and rural areas. In urban areas, since 1952, free medical system in government institutions and labor insurance system in the enterprise owned by the whole people were established. While in rural areas, cooperative medical service developed rapidly during Cultural Revolution period (1966-1976). The health care system which mainly depended on government, enterprise, collective organization and was "wide coverage, low standards, relatively fair" was established. World Health Organization supposed that China has created a model for developing countries to solve medical problems.

\subsubsection{Exploration period of health care system}

Since the reform and opening up in 1978, in urban areas, private and individual enterprises have been gradually developed, and state-owned enterprises profit have increasingly dropped. Thus, labor insurance system lost the economic foundation. In addition, the previous model that the enterprises pay for medical care cost brought about a big burden on its rapid developing. Accompanied by the enterprise restructuring, a large number of laid off workers appeared, facing with the problem of health care without insurance. There is an urgent need to establish the new model of health insurance suited the market economy development. In the late of 1980 s, our country tries to set up the basic medical insurance system for urban residents, which was widespread throughout our country at the early of 1990s. At present, the health insurance for urban workers and residents are available for most of citizens. Only the government employees can still enjoy free medical care. In addition, many other forms of commercial health insurance systems are available in China.

In rural areas, with the implementation of the reform of household contract responsibility system, the cohesion and production capacity of Production brigade or rural cooperative had weakened gradually. Thus, collective organization had gradually lost its economic supporting role for rural cooperative medical care. Cooperative medical faced the financial problem. Besides, many migrant workers swarm into cities, which formed a large group of mobile labors. However, cooperative medical care could not meet the need of mobile labors in medical care service. Finally, cooperative medical care was gradually turned to externalism or fell apart. Out-of-pocket for health care once again became the dominant way in rural areas, which greatly increased the burden on people and made them cannot totally enjoy public health service. The facts mentioned before arose the problems of difficult and high cost to access medical service.

\subsubsection{Improvement stage of health care system}

Many farmers lack of health insurance and cannot afford the heavy medical costs, resulting in many farmers become poor 
because of illness. For this problem, the central government has clearly point out that in rural areas, we have to gradually set up the new rural cooperative medical care system which can meet the requirement of the socialist market economy and the level of rural development, mainly dealing with serious illness. The new rural cooperative medical care system is established by government's organizing, leading and supporting, raising fund through multiple channels. Farmers participate in this system at their own will. In urban areas, for medical costs soaring and doctor-patient conflicts intensified, we have to actively study reform of the hospital management and medicine circulation system, rebuild the primary health care service system, so that the common residents can access to the medical care.

\subsection{Changes in Ideology and the Domestic Health Policies}

Ideology always plays a crucial part in human being's behavioral concept and in the choosing of the public policies as well as in forming them. The changes of China's Health Policies also imply the influences of the ideology to the health policies and fairness, which include "broad fairness", the tendency of market liberalization tendency and scientific thought of development.

\subsubsection{Ideology of Socialistic Broad Fairness plays a vital part in the forming of the thought of traditional healthy service}

As a powerful economy body, the city always in the leading position of reform and economic development. It is a common phenomenon that there is a gap between urban and rural in the level of sharing the public service, which was more common in the hard times. But as a socialist country, "fairness, liberty and democracy" should be stressed in China. Especially in the early days of foundation, having suffered from the huge gap between the rich and the poor as well as the severe exploitation, people were eager for the principle of "all men are equal", leading to their being unable to tolerate any unfairness, which contributed the forming of the ideology of "broad fairness".

As is mentioned above, the years of the Cultural Revolution were so important for the comprehensive development of the health care service. It met many peasants' need for the basic health care, which was closely linked to this "broad fairness", or equality conception in socialism. In the middle of $1960 \mathrm{~s}$, having noticed the atrophy of the rural cooperative medical service and the deterioration of the medical situation, Chairman Mao criticized the Health Department in public and pointed out that it didn't serve all the cock-bottom peasants and workers. Then, with a large scale of doctors "going to the countryside", and some "barefoot doctor" turning up, the medical resources leaned to the rural areas, which to a certain extent released the unfairness of the share in medical resources between the urban and rural. The possibility for rural residents' access to healthy service improved.

\subsubsection{Serious situation of the growing gap caused by reality and the sense of "balance equity"}

After the implement of reform and opening-up, especially after Deng Xiaoping came up with the policy that "some get rich first and then others follow" and "reaching the aim is more important than the way of reaching it", large changes took place in making and carrying out the policies of public medical service with idea of balancing fairness and efficiency. The government's function greatly weakened in the aspect of financial investment and management, which reduced the burden of the workers in the state-owned enterprises for medical costs. The accumulation and the distribution of the medical resources mainly depended on the market instead of the authorities. In this case, the new medical insurance model of urban workers insurance and urban citizens insurance was formed in the cities. Under the circumstances, in urban areas, medical insurances for urban workers and residents system were set up. While for some reasons, the medical insurance in the rural areas became a mere formality. Out-of-pocket for health care became the dominant way in rural areas. This is the impact of the market liberalism tendency to the choosing and reform of our healthy service policies. To some extent, it was away from the socialist core values of fairness.

\subsubsection{New healthy service reform under the guidance of "scientific thought of development"}

At the beginning of this century, our leaders came up with the slogans of "scientific outlook on development" and "build a harmonious society". The most influential point is that the 
difficulty in medical curing has been solved. The idea in dealing with balancing efficiency and fairness changes from "balancing equity" to "paying more attention to fairness". Therefore, the government has introduced a range of reforms in the medical service. In the urban, basic medical insurance is improved sufficiently. The coverage of it has a constant improvement. The medical aids have been widespread to solve the medical care problem for the poverty in urban areas. While, in rural areas, cooperative medical care service is adopted again with progressive regulations and improvements. As the cost is raised in the three aspects-individuals, the government and the local authority, the burden of the peasants in medical care service is released sharply, which solves the problem of "getting poverty due to illness". The new model of heath care reform and development fully reflects that the government is adjusting the health value. Equity replaces efficiency, becoming the dominant value, aimed to deal with the inefficiency and unfairness in health system.

\section{Rebalancing of equity and efficiency in the health reforming}

From the existing literature for the understanding of health equity point of view, there are two types: the process equity and the result equity. The former refers to the equity in the use of health financing and health care services; the latter refers to the health outcomes of fairness. Medical treatment is not the only or major factor that affect health care, but the inequity of financing and using (or accessibility) will worsen the extent of health inequalities. In the terms of efficiency, analysis can be done in the aspects of efficiency of resource use and medical costs benefit. Losses exist in both efficiency and equity in the current health system, which is interrelated to much faultiness of the system. Further system reform in the health care area should be strengthened in the following areas:

\subsection{Improvement of the equity in health care finance}

The equity in health care finance is reflected by the funding progressive level, the higher the degree of progressivism is, the more equitable the health-care financing will be. Studies have shown that in a country's health financing sources, the higher the proportion of public financing takes, medical financing can more easily show the progressive features. however, currently the health care financing in our country still accounts for very high proportion of residents share, financing is easy to form a "regressive", that is inequity of health care financing. This requires that governments should continue to increase health care investment, gradually reduce the pressure of private financing; also non-profit organizations and funds should be encouraged to involve in health care financing to form the social sources of financing.

\subsection{Enhancing the accessibility of medical services}

Urban and rural primary health care system should be reconstructed, thereby the pressure medical treatment would be diverted, and health care costs would be reduced, relieving the burden on patients. At present, as China's urban health care service model is maturing, government should promote the model and resources of health services to rural areas, particularly to the main areas where health care services are urgent needed, such as remote mountainous areas. Thus the urban-and-rural, interregional inequalities of the use of health care would be declined, then establish an "urban first, the rural second, urban-promoting-rural" universal health care strategy.

\subsection{Expediting Construction of the medical security system}

Medical insurance and medical health are closely related and influence each other, which is an important way to improve the fairness of health care and health services. On the one hand, it can provide a stable sources of fund for the general public to meet the multi-level medical needs; On the other hand, it is also conductive to the form of the external balance mechanism, standardize medical services, enhance the standard of health care, promote the reform of the medical and health system, and reinforce the medical institutions management. Moreover, in the social transformation process, attention should also be highly paid to the vulnerable groups in society. Enhancing the medical assistance and improving the welfare of these groups, is the centralized reflection of being kind to our social group. 


\subsection{Further improvement of the utilization of health resources}

The "separation of management from operation" Should be actively implemented to eliminate benefit coupling mechanism, the for-profit and nonprofit hospitals should be correctly oriented. We should actively explore the way that private capital enters the medical industry, to increase the supply of services, thus forming a good situation of competition and efficiency. Meanwhile, we should encourage the development of the applicability of medical equipment, focus on improving the efficiency of existing ones, increase government supervision, and introduce non-profit organizations and public to participate in service quality evaluation, to form a favorable social environment of public supervision, and promote the healthy development of medicine and health. Reforming the pharmaceutical distribution system, and steadily advancing the separation, will get rid of the terminal monopoly in pharmaceutical market by medical institutions.

\section{Conclusion}

Based on the basic process of health care policies transition in China, this paper discussed the relationship between ideology and the formulation of health policy. We hold the points that the subtle changes in ideology are related to the unfavorable phenomenon of "unfair and inefficient" appeared in health field during the period of economic transition. The main direction of future reform is that the concept value of health should be adjusted and policy implementation strategies need to be improved. First ,to improve the equity of health care financing; Second, to enhance the accessibility of medical services; third, to speed up the construction of the medical security system; finally, to enhance the efficiency of medical resource utilization deeply.

\section{References}

[1] Wang.L. On Priority: Liberty and Equality[J]. Social Science Journal, 2007, (5): $26 \sim 30$ (In Chinese)

[2] A.Wagstaff and E.V.Doorslaer. Equity in health care finance and delivery[M].
Handbook of Health Economics (Elsevier, Amsterdam) Chapter 34, 2000:1805-1833

[3] A.Wagstaff and R.Cookson. Equity in health[M]. Handbook of Health Economics(Elsevier, Amsterdam) Chapter 35, 2000:1866-1870

[4] R.Dworkin. Sovereign Virtue: the Theory and Practice of Equality[M]. Nan Jing: Jiangsu People's Publishing.LTD, 2003:135-140

[5] Cao.P. The Cooperative Medical System in countryside during People Commune Period[J]. Journal of the Party School of the Central Committee of the C.P.C, 2009,13(6) : 79 83 (In Chinese)

[6] Duan.DQ. The Choice and Realization of the Fair Value in the Field of Health care[J]. Chinese Health Economics, 2010,29(2) : $59 \sim 62$ (In Chinese)

[7] Wang.YZ. China's Hygiene Problems and Health Justice during the Transition Period[J]. China Industrial Economy, 2005, (12) : 56 63 (In Chinese)

[8] Zhao.Z. Measuring Health Inequality in China Using Self-Reported Health Stasus[C]. The 5th China Economics Annual Conference, Dec.2005 (In Chinese) 